\title{
Research on Head-box Liquid Level Precise Servo Control System of Twin Roll Casting Aluminum Alloy Strips Based on Laser Ranging
}

\author{
Jiaxi Liu* and Zhinan Mi \\ School of Mechanical Engineering, Tongji University, Shanghai 201804, China \\ ${ }^{*}$ Corresponding author
}

\begin{abstract}
There are defects in traditional liquid level control system of twin roll casting head-box, this study proposes one kind of liquid level precise control system for the head-box based on a combination of laser precise ranging and precise servo control system. Precise laser rangefinder implemented stable highprecision non-contact measurement of the molten aluminum level. A fast responsive and precise servo motion control system was constructed by linear slide module, AC servo driver and servo motion controller. The software of the servo control system for the liquid level was developed with a friendly human-machine interface, simplicity, efficiency, reliability by Delphi integrated development environment. The laboratory experiments and operations of the control system ensured rapid installation and commissioning on the production line. The system application shows that the control process is stable and reliable, and liquid level control error is not greater than $\pm 1.0 \mathrm{~mm}$.
\end{abstract}

Keywords - twin-roll casting head-box; laser precise ranging; liquid level; precise servo control; linear slide module

\section{INTRODUCTION}

Twin-roll casting combines solidifying and rolling into one production step for aluminum alloy strips [1]. The twin-roll casting process involves the melting, resting, refining of raw materials such as aluminum ingots, recycled scraps, intermediate alloys, metal additives, and finally the molten aluminum is cast and rolled into strips, it is well-known to be more cost-effective than conventional processes [1-3]. Horizontal twin-roll caster and vertical twin-roll caster are two typical casters. There are many factors that affect the quality of the cast-rolling products [1, 4-12], one of the important factors is the liquid level of the twin-roll casting head-box.

The liquid level of the head-box is controlled by the liquid level control system to maintain relatively constant static pressure of the molten aluminum alloy in the cast-rolling zone during cast-rolling. At present, there are mainly three kinds of the liquid level control systems in the twin-roll casting production, which are lever-type, buoy-type, and non-contact capacitive sensor type [13]. Due to the easy corrosion of the buoy, the shaft gap of the lever mechanical structure with relatively large mass, the lever-type liquid level control system has low control accuracy, short service life, slow response, and needing frequent maintenance. The buoy-type liquid level control system also has low accuracy because the buoy is apt to be corroded, and the buoy fluctuates along with the liquid level fluctuation. As the capacitance sensor is close to the molten aluminum alloy, it is difficult for the sensor to maintain a long time stable performance, which affects service life and measurement accuracy of the non-contact capacitive sensor liquid level control system.

Based on high-precision laser rangefinder and precise servo motion control system, the head-box liquid level new type control system will be developed.

\section{HARDWARE DESIGN OF THE HEAD-BOX LIQUID LEVEL CONTROL SYSTEM}

Aluminum alloy strip is the typical cast-rolling product. No matter horizontal twin-roll casting or vertical twin-roll casting, the cast-rolling production process is basically the same, as shown in Figure 1, No.5 is the head-box of the cast-rolling, it is the level of the molten aluminum level in No.5 that need to be precisely controlled.

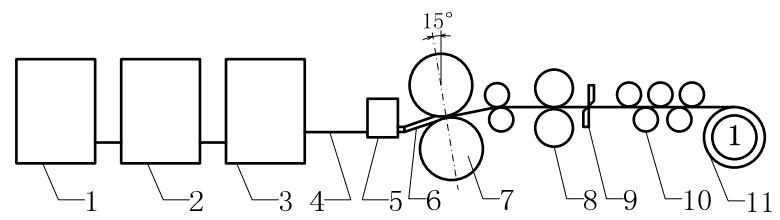

1-melting furnace; 2-rest furnace; 3-refining furnace; 4-flow groove; 5-headbox; 6-castrolling nozzle; 7-two roll caster; 8-clamping roll; 9-sheet shear; 10straightening machine; 11-coiler

FIGURE I. TWIN-ROLL CASTING PROCESS

\section{A. Hardware Design for Servo Control System}

According to the cast-rolling process, the molten aluminum alloy temperature in the head-box is about $695^{\circ}$, and therefore infrared radiation is generated around. Figure 2 shows the hardware design of the servo control system for the head-box level.

In the Figure 2, MSE-AL30 is laser rangefinder to measure the height from the molten aluminum alloy surface in the headbox to reference point of the sensor, the sensor range is $0.1 \mathrm{~m}$ $10 \mathrm{~m}$, accuracy is $\pm 1 \mathrm{~mm}$, resolution is $0.1 \mathrm{~mm}$, repeatability is $\pm 0.5 \mathrm{~mm}$, interface is RS232, supply voltage is 10 -30VDC. When the measuring range is less than $2 \mathrm{~m}$, the measuring accuracy can reach $\pm 0.8 \mathrm{~mm}$, and the repeatability can reach $\pm 0.3 \mathrm{~mm}$. 


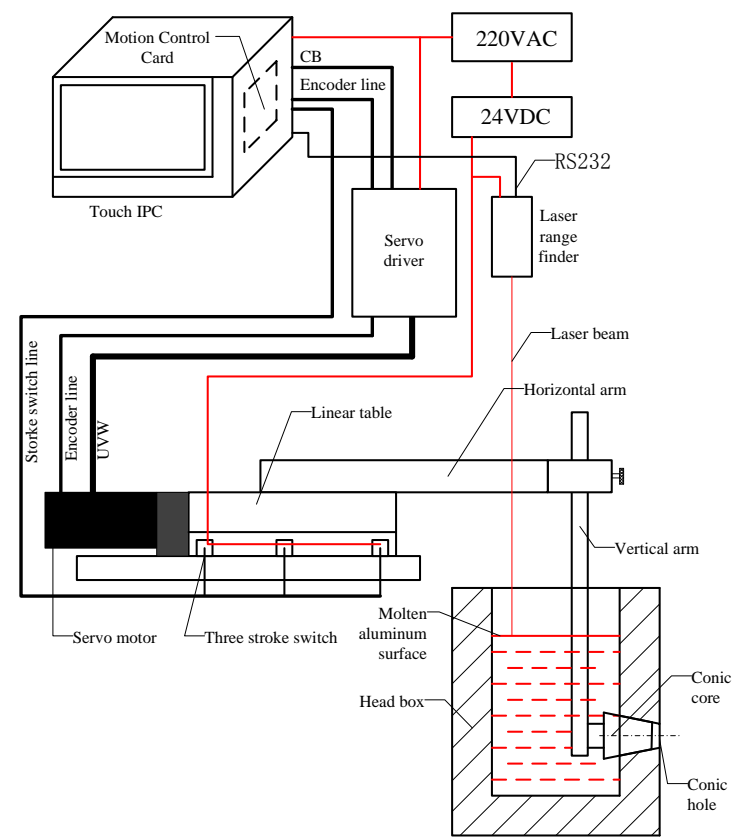

FIGURE II. HARDWARE DESIGN OF THE SERVO CONTROL SYSTEM

The linear slide uses linear sliding module KK6010C200A1F0CS1 of the HIWIN's company, and the ball screw lead is $10 \mathrm{~mm}$, repeatability is $\pm 0.01 \mathrm{~mm}$.

According to the inertia and torque matching method, Delta's 400-watt servo motor ECMA-C10604RS and servo driver ASD-A2-0421 were selected. The servo motor was equipped with a 20-bit incremental optical encoder.

The servo motion control Card is GT-200-SG-PCI-G of Googol's company, which can control two AC servo motors and have 16 optically isolated universal digital signal input and output respectively.

Industrial personal computer (IPC) is Advantech Micro ATX motherboard AIMB-501, touch screen is 10.4 inches of Advantech IDK-1110 with USB interface.

\section{B. Analysis of Hardware Accuracy of the Control System}

The hardware accuracy of the control system is the basis for the control of the head-box liquid level. In the hardware closed loop of the control system, the laser rangefinder has a measurement accuracy of $\pm 0.8 \mathrm{~mm}$ and a repeatability of $\pm 0.3 \mathrm{~mm}$. The linear slide repositioning accuracy is $\pm 0.01 \mathrm{~mm}$. The pulse equivalent $\delta$ of the servo motor and the linear slide is: $10 \mathrm{~mm} /$ pulse per revolution, and that is $10 / 2^{20}$ (mm/pulse), that also is $9.536743 \times 10^{-6}$ (mm/pulse), and so the pulse equivalent is sufficiently small. Therefore, the hardware accuracy of the head-box level servo control system is mainly determined by the accuracy of the laser rangefinder.

\section{SOFTWARE DESIGN FOR THE CONTROL SYSTEM}

The head-box liquid level servo control system software was developed by the motion controller dynamic link library (DLL) of Googol in the Delphi Integrated Development Environment (IDE). The software includes seven main functional parts: human-machine interface (HMI), RS232 serial communication, liquid level measurement, liquid level control algorithm, servo motion control, embedded soft PLC, and fault alarm.

The human-machine interface is shown in Figure 3. It is the foreground program of the control system software to display information and set parameters. As shown in Figure 3, touching the "settings" button goes to the parameter setting page.

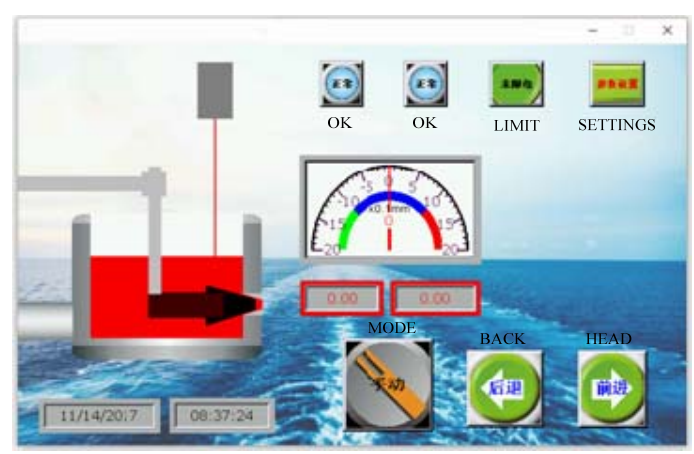

FIGURE III. HUMAN MACHINE INTERFACE

The other major parts of the program are equivalent to the background programs, which can be programmed in Delphi's time control TTimer. Each part can be implemented by processes or functions. The main flow of these processes or functions is shown in Figure 4.

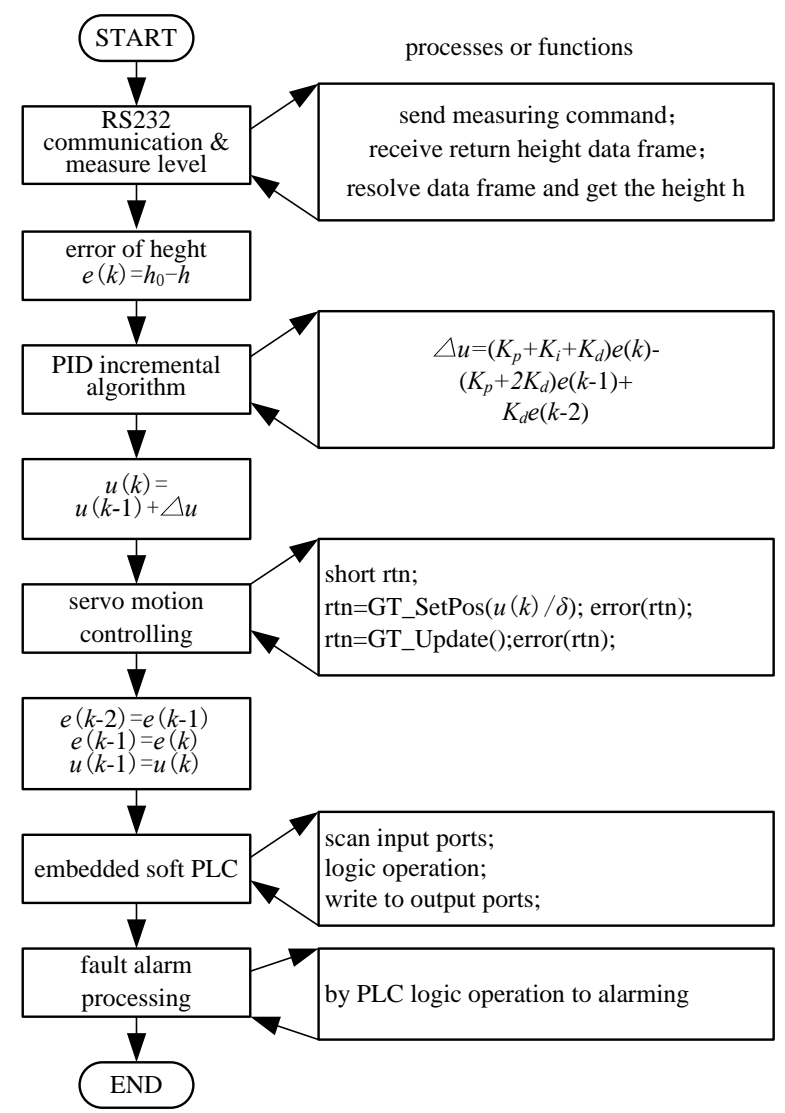

FIGURE IV. PROGRAM FLOW CHART OF THE OTHER MAJOR PARTS 
The servo motion control program needs to call the dynamic link library (DLL) functions to initialize the servo motion control card in the relevant part of the foreground program (such as to select axis, and control mode, to set acceleration, etc.). In Figure 4, only the control quantity $u(k)$ is calculated by PID algorithm, and the $u(k)$ is then converted into the number of pulses $(u(k) / \delta)$ which is assigned to the servo movement position function, and the servo control system automatically completes the position servo control.

\section{EXPERIMENTAL DEVICE AND EXPERIMENT}

\section{A. Experimental Device}

Aluminum alloy strip cast-rolling is continuous production, and the molten aluminum alloy has high temperature. These characteristics determine that the installation of the head-box liquid level servo control system can only be performed during melting furnace maintenance. The commissioning of this control system can only be carried out after the initial castrolling stage, and the debugging time is as short as possible. Therefore, the control system must be fully tested and debugged to keep it running reliably before going online for installation. Figure 5a shows the simple, economical and practical experimental device which was established for offline debugging and experiment.

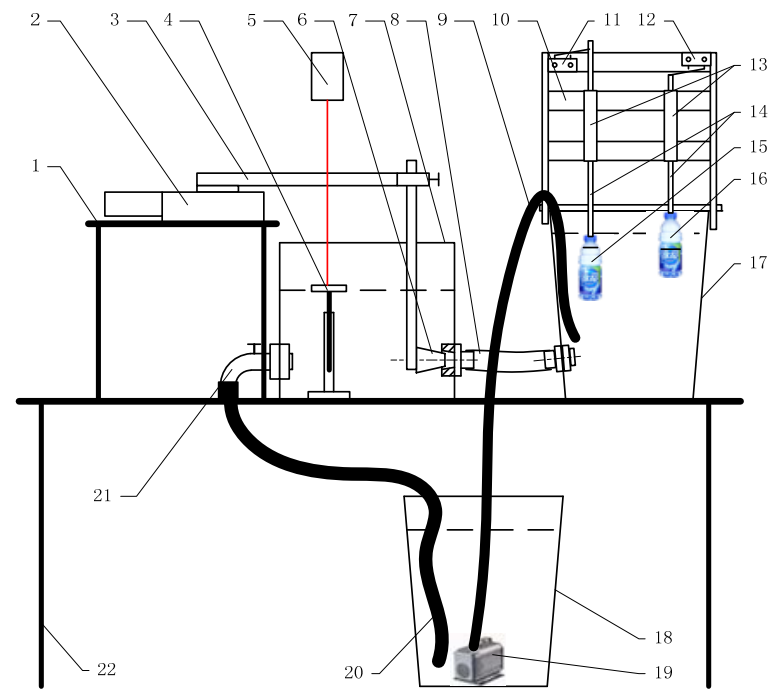

(A)

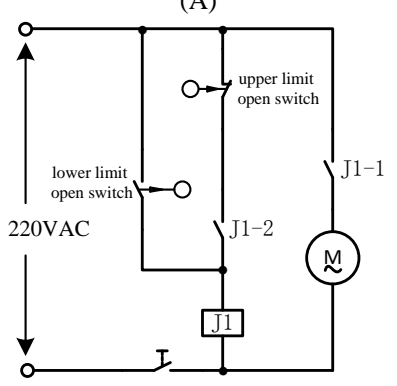

(B)

FIGURE V. (A)EXPERIMENT DEVICE OF THE WATER LEVEL CONTROL SYSTEM (B)AUTOMATIC CONTROL SCHEMATIC DIAGRAM OF THE WATER LEVEL UPPER AND LOWER LIMITS
As shown in Figure 5a, 1-linear slide mounting bracket, 2linear slide, 3-controll cone mounting arm, 4-laser floating reflector and positioning guide, 5-laser rangefinder, 6-control cone, 7-water box, 8-water pipe and pipe connector, 9-water supply pipe, 10-Wooden mounting bracket, 11-stroke lower limit switch, 12-stroke upper limit switch, 13-PVC guide pipes, 14-PVC rods, 15-lower limit float bottle, 16-upper limit float bottle, 17,18-water buckets, 19-submersible pump, 20-water return pipe, 21- water-tap, 22-test table. As shown in Figure 5b, it is the automatic control schematic diagram of the water level upper and lower limits.

\section{B. PID Servo Control Theory of the Liquid Level}

As shown in the Figure 2, liquid surface height $h$ is the distance from the molten aluminum surface to the laser rangefinder, the $h$ is measured by the laser rangefinder. The $h$ is compared with the setting height $h_{0}$ to obtain the height error $e(k)$, that is $e(k)=h_{0}-h$, as shown in the Figure 4, the control quantity $u(k)$ is calculated out according to the PID algorithm. Then the servo motor rotation is controlled by $u(k)$ to drive the conic core to move to adjust the opening of the cone valve to achieve the liquid level servo control.

\section{Experiment and Analysis}

First, the PID parameters are set based on experience, and then the PID parameters are frequently tuned according to the control effect. When the proportional coefficient $K_{\mathrm{p}}$ is about 2.0, the integral coefficient $K_{\mathrm{i}}$ is about 0.01 , and the differential coefficient $K_{\mathrm{d}}$ is 0.0 , and when the height difference between the upper and lower water level limits in the water bucket 17 is less than $30 \mathrm{~mm}$, the continuous running of the control system for three days has shown that the control system is very stable, and the error of water level in water box 7 is not more than $\pm 1.5 \mathrm{~mm}$.

More tests have shown that if the error of the water level in the water box 7 hopes to be further reduced, it is necessary to further reduce the height difference between the upper and lower water level limits in the water bucket 17 and the height difference between the water level in the water bucket 17 and the water box 7 .

After the liquid level servo control system was tested on the laboratory experiment device, it was very quick and convenient installed the control system on the aluminum alloy strip castrolling production line, and the debugging was successful at one time, the control error was not greater than $\pm 1.0 \mathrm{~mm}$ for the molten aluminum alloy level.

The control accuracy of the molten aluminum alloy level is higher than that of the water level in the laboratory experiment. The main reasons are that the viscosity of the molten aluminum alloy is greater than that of water, and that changing rate of the molten aluminum alloy level in the head-box on the production line is slower than the changing rate of water level in the water box 7 in the laboratory experiment.

\section{CONCLUSIONS}

This precise servo control system was studied based on laser rangefinder for the head-box molten aluminum alloy level 
in the cast-rolling production line. Laboratory experiments and practical producing control show that the control system overcomes the shortcomings of the traditional cast-rolling head-box level control system, and that this system has the characteristics of fast response, high control accuracy, good stability, and friendly man-machine interface, and a very good practical value and promotion value.

\section{REFERENCES}

[1] G. Kurz, J. Bohlen, L. Stutz, D. Letzig, K. U. Kainer, "Influence of Temperature and Rolling Speed on Twin Roll Cast Strip,” Magnesium Technology, 2013, pp.365-366.

[2] J. Roberte Sanders, "Continuous Casting for Aluminum Sheet: a Product Perspective,” JOM, 2012, vol. 64 (2), pp. 292-301.

[3] Lee Yunsoo, Kim Hyoungwook, Cho Jaehyung, Chun Sehwan, "Coupled Thermal Fluid Mechanics Analysis of Twin Roll Casting of A7075 Aluminum Alloy,” Met. Mater. Int., 2017, vol. 23（5） , pp. 923929.

[4] Chen Gang, Xu Guangming, "Effects of melt pressure on process stability and bonding strength oftwin-roll cast steel/aluminum clad sheet,” Journal of Manufacturing Processes , 2017, vol. 29, pp. 438-446.

[5] O. Grydin, M. Stolbchenko, F. Nurnberger, M. Schaper, "Influence of Hot Deformation on Mechanical Propertiesand Microstructure of a Twin-Roll Cast Aluminum Alloy EN AW-6082,” Journal of Materials Engineering and Performance, 2014, vol. 23(3), pp. 937-943.

[6] I. Bayanddorian, Y. Huang, Z. Fan, S. Pawar, X. Zhou, G.E Thompon, "The Impact of Melt-Conditioned Twin-Roll Casting onthe Downstream Processing of an AZ31 Magnesium Alloy,” Metallurgical and Materials Transactions A, 2012, vol. 43A, pp. 1035-1047.

[7] Jiang Chengcan, Rui Yannian, "Thermodynamic Behavior Research Analysis of Twin-roll CastingLead Alloy Strip Process,” Chin. J. Mech. Eng., 2017, vol. 30, pp. 352-362.

[8] Chen Shoudun, Chen Jingchao, "Simulation of microstructures in solidification of aluminum twin-rollcasting," Transactions of Nonferrous Metals Society of China, 2012, vol. 22, pp. 1452-1456.

[9] Chen Shoudun, Chen Jingchao, "Micromodel of Simulation on TwinRoll Continuous Casting Thin Strip Solidification Structure,” Rare Metal Materials and Engineering, 2013, vol. 42(1), pp. 0014-0018.

[10] OUYang Xiangrong, Yi Youping, "Design and Analysis of Cooling Capability of Twin Roll Caster for Aluminum Alloy Strips," Nonferrous Metals Processing, 2015, vol. 44 (3), pp. 48-50. (in Chinese )

[11] OUYang Xiangrong, "Analysis and Caculation of Casting Rolling Force Tilting Twin Roll Strip Caster,” Nonferrous Metals Processing, 2016, vol. 45 (4), pp. 53-54,59. (in Chinese )

[12] Hou Bo, Li Yongchun, Li Jianrong, Xie Shuisheng, “Aluminum Alloy Continuous Cast Rolling and Continuous Casting and Rolling Technology,” Beijing, China: Metallurgical Industry Press, 2010. (in Chinese ) 